\title{
Neurological Examination for Diagnosis and Prognosis of Spinal Disorders in Dogs
}

\author{
G.S. Khante*, S.V. Upadhye, P.T. Jadhao, N.P. Dakshinkar, B.M. Gahlod, \\ S.K. Sahatpure and N.V. Kurkure \\ Department of Veterinary Surgery \& Radiology, Nagpur Veterinary College, \\ Seminary Hills, Nagpur, India \\ *Corresponding author
}

\section{A B S T R A C T}

The research on neurological examination for diagnosis of spinal disorders in dogs was undertaken at the College Hospital of Nagpur Veterinary College, Nagpur during 2015 to

Keywords

Neurological examination, Spinal disorders, Prognosis

Article Info

Accepted:

07 December 2018

Available Online:

10 January 2019
2018 on fifty-two clinical cases of dogs with the aim to study efficacy of individual neurological tests in diagnosing the cases of spinal affections. The dogs were treated either by medicinal treatment or surgery. The conservative medicinal treatment included injections of methyl prednisolone acetate (group I) or methyl prednisolone succinate (group II), @ 30mg/kg as per requirement whereas surgical group included hemilaminectomy in spinal compression (group III) and spinal fixation in fractures or luxation (group IV). Among the spinal reflexes, myotatic reflexes i.e. patellar, cranial tibial, sciatic and gastrocnemius reflexes and flexor i.e. pedal or withdrawal reflexes were evaluated and classified on the day of presentation and at scheduled interval during the treatment. The results indicated that these neurological tests proved very useful in determining the grades of the neurological deficits and it was possible to judge the response to treatment on the basis of these tests proving their efficiency.

\section{Introduction}

The nervous system of animals helps animal in sensing and reacting to the surroundings. Any abnormality hampering this may result in manifestation of symptoms which vary depending upon the location and severity of the disorder. The disorders of spinal cord, injuries and resultant neurologic deficit are common in dogs and the most common causes of such injuries are automobile accidents, falls from height, animal conflicts or less commonly the gunshot injuries (Nagaraja et al., 2014). The diagnosis requires a systemic approach and includes the anamnesis, symptoms, physical and neurological examinations followed by a diagnostic plan that incorporates selected ancillary diagnostic procedures. The neurological examination helps in anatomical localization of the lesions which in turn assist in deciding the diagnostic modality to be used and the therapeutic measures to be undertaken (Shares and Braund, 1993). In view of these facts, it was 
decided to compare the assistance of neurological spinal reflexes tests for assessing the impact of treatment in the neurological deficits.

\section{Materials and Methods}

The dogs suffering from posterior paresis or the hindquarter weakness and reported at College Hospital of Nagpur Veterinary College, Nagpur during 2015 to 2018 were included in the study. A thorough neurological examination was performed in individual cases and the diagnosis of the disorder was confirmed on the basis of radiographic examinations in all and CT and MRI examinations in a few cases. The dogs were treated either by medicinal treatment with injections of methyl prednisolone acetate (group I) or methyl prednisolone succinate (group II);or surgical treatment was undertaken by using appropriate methods i.e. hemilaminectomy in spinal compression cases(group III) or spinal stabilization in cases of fractures or luxation (group IV).

The spinal reflexes examinations included, myotatic reflexes i.e. patellar, cranial tibial, sciatic and gastrocnemius reflexes and flexor reflexes i.e. pedal or withdrawal reflexes. They were evaluated and classified as -

Patellar, Cranial Tibial, Sciatic and Gastrocnemius reflexes -Score 0- Absent, Score 1- Present but reduced, Score 2Normal, Score 1- Exaggerated, Score 0Exaggerated clonus.

Withdrawal reflexes-Score 1- Absent, Score 2Mild/only superficial, Score 3- Strong superficial and deep.

The scores of various tests were evaluated in all the dogs of all groups on the day of presentation to evaluate whether the dogs showing posterior paresis and hindquarter weakness shows changes in these parameters on the day of presentation and whether the scores varied with the grades. Similarly, the scores were compared between the group I and II (medicinal treatment groups) and between group III and IV (surgical treatment groups) and between the intervals at day 1, day 15, day 30 and day 90 after the initiation of therapy in order to assess the progress of the condition.

The data was analyzed by using two-way Factorial Randomized Block Design (Snedecor and Cochran, 1994) and results are presented and discussed here.

\section{Results and Discussion}

The results of various neurological tests were as follows-

\section{Patellar reflex}

The data regarding the scores of patellar reflexes in various groups on day of presentation, comparison between group I and II and between group III and IV is presented in Table 1.

The mean patellar reflex score on day 0 in all the groups was $1.00 \pm 0.00$ indicating reduced or exaggerated patellar reflex at the time of presentation. Thus, the patellar reflex was adversely affected in spinal disorders. However, the differences between the groups were non-significant.

The mean patellar reflex score in group I showed regular increasing trend, improved gradually and the score after 3 months was $2.0 \pm 0.00$ indicating normal patellar reflex in the group. Similar trend was observed in group II wherein the score improved to $1.8 \pm 0.10$ at the end of observation period indicating more or less similar effect of both the conservative treatment modalities. It was 
further observed that the differences between the group I and II were non-significant, however, there was significant differences between the scheduled intervals indicating gradual and positive impact of the treatment. The mean patellar reflex score in group III exhibited regular increasing trend and the patellar reflex gradually improved and the score after 3 months was $2.00 \pm 0.00$ indicating that all the dogs showed normal reflex. Similar trend was observed in group IV wherein the score improved from $1.00 \pm 0.00$ to $2.00 \pm 0.00$ at the end of observation period. It was further observed that the differences between the group III and IV were nonsignificant indicating that both the surgical modalities had similar improvement in the score. However, the differences within the respective groups at different scheduled intervals were significant. In both the groups, the normal patellar reflex was noted on $30^{\text {th }}$ day that continued till the end of observation period. Platt and Olby (2004) recorded that the spinal reflexes were normal to increased in spinal affections.

\section{Cranial tibial reflex}

The data regarding the mean scores of cranial tibial reflexes in various groups on day of presentation, comparison between group I and II and between group III and IV is presented in Table 2.

The pooled average of mean cranial tibial reflex score on day 0 in all the groups was $1.00 \pm 0.00$ indicating adverse effect of the disorder, however, the differences between the groups were non-significant.

The mean cranial tibial reflex score in group I showed regular increasing trend, improved gradually and the score after 3 months was $1.90 \pm 0.07$ indicating certain improvement in cranial tibial reflex in the group. Similar trend was observed in group II wherein the score improved to $1.82 \pm 0.10$ at the end of observation period indicating more or less similar effect of both the conservative treatment modalities. It was further observed that the differences between the group I and II were non-significant, however, there was significant differences between the scheduled intervals indicating gradual and positive impact of the treatment. The mean cranial tibial reflex score in group III on day 0 was $1.00 \pm 0.00$ which exhibited regular increasing trend and the reflex gradually improved and the score after 30 days was $2.00 \pm 0.00$ and continued till the end of observation period indicating that all the dogs showed normal reflex. Similar trend was observed in group IV wherein the score improved from $1.00 \pm 0.00$ to $2.00 \pm 0.00$ on $30^{\text {th }}$ day and continued till the end of observation period indicating positive impact of the surgical modalities in both the groups. It was further observed that the differences between the group III and IV were non-significant indicating that both the surgical modalities had similar improvement in the score. The differences within the respective groups at different scheduled intervals were significant. In both the groups, the normal cranial tibial reflex was achieved at the end of observation period. Wilkens et al., (1998) also observed exaggerated reflexes of the hind limbs in spinal cord affections besides hyperaesthesia. However, Platt and Olby (2004) observed normal to increased response in spinal nerves.

\section{Sciatic reflex}

The data regarding the scores of sciatic reflex in various groups on day of presentation, comparison between group I and II and between group III and IV is presented in Table 3.

The mean sciatic reflex scores on day 0 in all groups was adversely affected in spinal disorder cases. The differences between groups on day 0 were non-significant. 
The mean sciatic reflex score in group I and group II showed regular increasing trend, improved gradually indicating certain improvement in sciatic reflex in the group. It was further observed that the differences between the group I and II were nonsignificant, however, there was significant differences between the scheduled intervals indicating gradual and positive impact of the treatment.

The mean sciatic reflex score in group III exhibited regular increasing trend up to day 15 and the score after 15 days remained at $2.00 \pm 0.00$ till the end of observation period indicating that all the dogs showed normal reflex. Similar trend was observed in group IV wherein the score improved from $1.17 \pm 0.17$ to $2.00 \pm 0.00$ on $30^{\text {th }}$ day and continued till the end of observation period indicating positive impact of the surgical modalities in both the groups. It was further observed that the differences between the group III and IV were non-significant indicating that both the surgical modalities had similar improvement in the score. However, the differences within the respective groups at different scheduled intervals were significant. In group III, the sciatic reflex returned to normalcy on day 15 whereas it achieved normalcy on day 30 in group IV.

Thus, it was concluded that the sciatic reflex was adversely affected and mostly was exaggerated in all the groups and there was progressive improvement during the course of treatment. This was obvious since exaggerated response indicate lesion cranial to the spinal cord segment L6-L7 and during the present investigation, the lesions were cranial to L6L7 in almost all cases. The findings are in corroboration with the observations of Wilkens et al., (1998) who reported that the spinal reflexes of the hind limbs were exaggerated in dogs suffering from hind quarter paralysis. However, Platt and Olby (2004) observed normal to increased response.

\section{Gastrocnemius reflex}

The data regarding the scores of gastrocnemius reflex in various groups on day of presentation, comparison between group I and II and between group III and IV is presented in Table 4. The mean gastrocnemius reflex scores on day 0 in all the groups exhibited reduced to exaggerated response and the differences were highly significant differences between all the groups on day 0 .

The mean gastrocnemius reflex score in group I showed regular increasing trend, improved gradually and the score after 3 months was $2.00 \pm 0.00$ indicating complete normal reflex in this group. In group II, the score improved to $1.89 \pm 0.08$ on $15^{\text {th }}$ day. However, it again decreased gradually and the score was $1.71 \pm 0.11$ at the end of observation period indicating that group I had better improvement in gastrocnemius reflex score as compared to group II. It was further observed that the differences between the group I and II were non-significant, however, there was significant differences between the scores at scheduled intervals indicating gradual and positive impact of the treatment. The interaction between the groups and intervals also showed significant differences indicating that the both the treatment modalities had different success rates in improving the gastrocnemius reflex scores. The mean gastrocnemius reflex score in group III exhibited regular increasing trend up to day 30 and the score after 30 days indicated that all the dogs showed normal gastrocnemius reflex. The group IV dogs showed irregular, undulating trend wherein the score improved from $1.50 \pm 0.22$ to $1.67 \pm 0.21$ on day 1 but again decreased on day 15 and then gradually improved and returned to normalcy at the end of observation period. Thus, although fluctuating, this surgical group also indicated positive impact. It was further observed that the differences between the group III and IV were non-significant indicating that both the surgical modalities had 
similar improvement in the score. However, the differences within the respective groups at different scheduled intervals were significant. In group III, the gastrocnemius reflex returned to normalcy on day 30 whereas it achieved normalcy after 3 months in group IV. The interaction between the groups and intervals also showed significant differences indicating that the both the treatment modalities had different success rates in improving the gastrocnemius reflex scores. The changes in hind limb reflexes in hind quarter paralysis has been documented by Wilkens et al., (1998) who observed exaggerated response in dogs suffering from hind quarter paresis whereas Platt and Olby (2004) observed that the clinical features of affection of T3-L3 spinal segment included symptoms associated with UMN deficits of hindlimb and charectorised by ataxia, proprioceptive deficit and paraplegia.

\section{Withdrawal reflex}

The data regarding the mean scores of withdrawal reflex or nociceptive reflex in various groups on day of presentation, comparison between group I and II and between group III and IV is presented in Table 5 .

The mean withdrawal reflex scores on day 0 in all groups indicated absence or minimal reflex. Therefore, it was observed that the sciatic reflex was adversely affected in posterior paresis and hind quarter weakness cases in most of the cases. The statistical analysis however indicated non-significant differences between all the groups on day 0 indicating that there was no significant difference for this reflex due to severity of grades of neurological deficit.

Table.1 Comparison of mean patellar reflex between conservative management groups (group I and group II), between surgical management groups (group III and group IV) and between different groups on day 0

\begin{tabular}{|c|c|c|c|c|c|c|}
\hline & \multicolumn{6}{|c|}{ Mean patellar reflex scores $( \pm \mathrm{SE})$} \\
\hline \multirow[t]{2}{*}{ Group } & \multicolumn{5}{|c|}{ Interval (Days) } & \multirow{2}{*}{$\begin{array}{c}\text { Pooled } \\
\text { average } \\
\text { (Groups) }\end{array}$} \\
\hline & Day 0 & Day 1 & Day 15 & Day 30 & Day 90 & \\
\hline Group - I & $1.00 \pm 0.00$ & $1.27 \pm 0.10$ & $1.77 \pm 0.09$ & $1.95 \pm 0.05$ & $2.0 \pm 0.00$ & $1.60 \pm 0.05$ \\
\hline Group - II & $1.00 \pm 0.00$ & $1.39 \pm 0.12$ & $1.72 \pm 0.11$ & $1.78 \pm 0.10$ & $1.8 \pm 0.10$ & $\mathbf{1 . 5 4} \pm 0.05$ \\
\hline $\begin{array}{c}\text { Pooled } \\
\text { average } \\
\text { (Intervals) }\end{array}$ & $1.00^{\mathrm{a}} \pm 0.00$ & $1.33^{b} \pm 0.08$ & $1.75^{\mathrm{c}} \pm 0.07$ & $1.88^{d} \pm 0.05$ & $1.92^{\mathrm{e}} \pm 0.04$ & \\
\hline \multicolumn{7}{|c|}{ Critical Difference (C.D.) for interval: $\mathbf{0 . 0 2 1 7 0}$} \\
\hline $\begin{array}{c}\text { Group - } \\
\text { III }\end{array}$ & $1.00 \pm 0.00$ & $1.00 \pm 0.00$ & $1.50 \pm 0.22$ & $2.00 \pm 0.00$ & $2.00 \pm 0.00$ & $\mathbf{1 . 4 8} \pm 0.09$ \\
\hline $\begin{array}{c}\text { Group - } \\
\text { IV }\end{array}$ & $1.00 \pm 0.00$ & $1.17 \pm 0.17$ & $1.33 \pm 0.21$ & $2.00 \pm 0.00$ & $2.00 \pm 0.00$ & $1.42 \pm 0.10$ \\
\hline $\begin{array}{c}\text { Pooled } \\
\text { average } \\
\text { (Interval) }\end{array}$ & $1.00^{a} \pm 0.00$ & $\mathbf{1 . 0 8}^{\mathrm{b}} \pm \mathbf{0 . 0 8}$ & $1.42^{c} \pm 0.15$ & $2.00^{\mathrm{df}} \pm 0.00$ & $2.00^{\mathrm{ef}} \pm 0.00$ & \\
\hline \multicolumn{7}{|c|}{ Critical Difference (C.D.) for interval: 0.06481} \\
\hline \multicolumn{7}{|c|}{ Pooled average Gr I to Gr IV on day $0: 1.00 \pm 0.00$} \\
\hline
\end{tabular}


Table.2 Comparison of mean cranial tibial reflex between conservative management groups (group I and group II), between surgical management groups (group III and group IV) and in different groups on Day 0

\begin{tabular}{|c|c|c|c|c|c|c|}
\hline \multirow{3}{*}{ Group } & \multicolumn{6}{|c|}{ Mean cranial tibial reflex scores $( \pm \mathrm{SE})$} \\
\hline & \multicolumn{5}{|c|}{ Interval (Days) } & \multirow{2}{*}{$\begin{array}{l}\text { Pooled } \\
\text { average } \\
\text { (Groups) }\end{array}$} \\
\hline & Day 0 & Day 1 & Day 15 & Day 30 & Day 90 & \\
\hline Group - I & $1.00 \pm 0.00$ & $1.45 \pm 0.11$ & $1.82 \pm 0.08$ & $1.86 \pm 0.07$ & $1.90 \pm 0.07$ & $1.61 \pm 0.05$ \\
\hline Group - II & $1.00 \pm 0.00$ & $1.28 \pm 0.11$ & $1.67 \pm 0.11$ & $1.78 \pm 0.10$ & $1.82 \pm 0.10$ & $1.51 \pm 0.05$ \\
\hline $\begin{array}{l}\text { Pooled average } \\
\text { (Interval) }\end{array}$ & $1.00^{a} \pm 0.00$ & $1.38^{b} \pm 0.08$ & $1.75^{c} \pm 0.07$ & $1.83^{\mathrm{d}} \pm 0.06$ & $1.87^{\mathrm{e}} \pm 0.06$ & \\
\hline \multicolumn{7}{|c|}{ Critical Difference (C.D.) for interval: 0.02339} \\
\hline Group - III & $1.00 \pm 0.00$ & $1.00 \pm 0.00$ & $1.50 \pm 0.22$ & $2.00 \pm 0.00$ & $2.00 \pm 0.00$ & $1.48 \pm 0.09$ \\
\hline Group - IV & $1.00 \pm 0.00$ & $1.17 \pm 0.17$ & $1.33 \pm 0.21$ & $2.00 \pm 0.00$ & $2.00 \pm 0.00$ & $1.42 \pm 0.10$ \\
\hline $\begin{array}{l}\text { Pooled average } \\
\text { (Interval) }\end{array}$ & $1.00^{\mathrm{a}} \pm 0.00$ & $1.08^{b} \pm 0.08$ & $1.42^{\mathrm{c}} \pm 0.15$ & $2.00{ }^{\mathrm{df}} \pm 0.00$ & $2.00^{\mathrm{et}} \pm 0.00$ & \\
\hline \multicolumn{7}{|c|}{ Pooled average Gr I to Gr IV on day $0: 1.00 \pm 0.00$} \\
\hline
\end{tabular}

Table.3 Comparison of mean sciatic reflex between conservative management groups (group I and group II), between surgical management groups (group III and group IV) and in different groups on Day 0

\begin{tabular}{|c|c|c|c|c|c|c|}
\hline \multirow{3}{*}{ Group } & \multicolumn{6}{|c|}{ Mean sciatic reflex scores $( \pm \mathrm{SE})$} \\
\hline & \multicolumn{5}{|c|}{ Interval (Days) } & \multirow{2}{*}{$\begin{array}{l}\text { Pooled } \\
\text { average } \\
\text { (Groups) }\end{array}$} \\
\hline & Day 0 & Day 1 & Day 15 & Day 30 & Day 90 & \\
\hline Group - I & $1.45 \pm 0.11$ & $1.59 \pm 0.11$ & $1.82 \pm 0.08$ & $1.82 \pm 0.08$ & $1.86 \pm 0.08$ & $1.71 \pm 0.04$ \\
\hline Group - II & $1.39 \pm 0.12$ & $1.72 \pm 0.11$ & $1.78 \pm 0.10$ & $1.83 \pm 0.09$ & $1.88 \pm 0.08$ & $1.72 \pm 0.05$ \\
\hline $\begin{array}{l}\text { Pooled } \\
\text { average } \\
\text { (Interval) }\end{array}$ & $1.43^{\mathrm{a}} \pm 0.08$ & $1.65^{b} \pm 0.08$ & $1.80^{\mathrm{cf}} \pm 0.06$ & $1.83^{\mathrm{df}} \pm 0.06$ & $1.87^{\mathrm{e}} \pm 0.06$ & \\
\hline \multicolumn{7}{|c|}{ Critical Difference (C.D.) for interval: $\mathbf{0 . 0 2 7 0 3}$} \\
\hline Group - III & $1.33 \pm 0.21$ & $1.50 \pm 0.22$ & $2.00 \pm 0.00$ & $2.00 \pm 0.00$ & $2.00 \pm 0.00$ & $1.76 \pm 0.08$ \\
\hline Group - IV & $1.17 \pm 0.17$ & $1.33 \pm 0.21$ & $1.67 \pm 0.21$ & $2.00 \pm 0.00$ & $2.00 \pm 0.00$ & $1.58 \pm 0.10$ \\
\hline $\begin{array}{l}\text { Pooled } \\
\text { average } \\
\text { (Interval) }\end{array}$ & $1.25^{\mathrm{a}} \pm 0.13$ & $1.42^{b} \pm 0.15$ & $1.83^{c} \pm 0.11$ & $2.00^{\mathrm{df}} \pm 0.00$ & $2.00^{\mathrm{ef}} \pm 0.00$ & \\
\hline \multicolumn{7}{|c|}{ Critical Difference (C.D.) for interval: $\mathbf{0 . 0 8 5 1 8}$} \\
\hline & Ir I to $G$ & 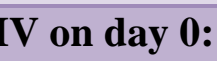 & $20+0$ & & & \\
\hline
\end{tabular}


Table.4 Comparison of mean gastrocnemius reflex between conservative management groups (group I and group II), between surgical management groups (group III and group IV) and in different groups on Day 0

\begin{tabular}{|c|c|c|c|c|c|c|}
\hline \multirow{3}{*}{ Group } & \multicolumn{6}{|c|}{ Mean gastrocnemius reflex scores $( \pm \mathrm{SE})$} \\
\hline & \multicolumn{5}{|c|}{ Interval (Days) } & \multirow{2}{*}{$\begin{array}{l}\text { Pooled } \\
\text { average } \\
\text { (Groups) }\end{array}$} \\
\hline & Day 0 & Day 1 & Day 15 & Day 30 & Day 90 & \\
\hline Group - I & $1.14^{\mathrm{A}} \pm 0.07$ & $1.32 \pm 0.10$ & $1.68 \pm 0.10$ & $1.86 \pm 0.07$ & $2.00 \pm 0.00$ & $1.60 \pm 0.05$ \\
\hline Group - II & $1.00^{\mathrm{BE}} \pm 0.00$ & $1.44 \pm 0.12$ & $1.89 \pm 0.08$ & $1.83 \pm 0.09$ & $1.71 \pm 0.11$ & $1.57 \pm 0.05$ \\
\hline $\begin{array}{c}\text { Pooled } \\
\text { average } \\
\text { (Interval) }\end{array}$ & $1.08^{\mathrm{a}} \pm 0.04$ & $1.38^{b} \pm 0.08$ & $1.78^{c} \pm 0.07$ & $1.85^{\mathrm{df}_{ \pm 0.06}}$ & $1.87^{\mathrm{ef}} \pm 0.06$ & \\
\hline \multicolumn{7}{|c|}{ Critical Difference (C.D.) for interaction:0.00592. For interval: 0.02368} \\
\hline $\begin{array}{l}\text { Group - } \\
\text { III }\end{array}$ & $1.00^{\mathrm{CE}} \pm 0.00$ & $1.33 \pm 0.21$ & $1.67 \pm 0.21$ & $2.00 \pm 0.00$ & $2.00 \pm 0.00$ & $1.59 \pm 0.09$ \\
\hline Group - IV & $1.50^{\mathrm{D}} \pm 0.22$ & $1.67 \pm 0.21$ & $1.00 \pm 0.00$ & $1.50 \pm 0.29$ & $2.00 \pm 0.00$ & $1.50 \pm 0.10$ \\
\hline $\begin{array}{c}\text { Pooled } \\
\text { average } \\
\text { (Interval) }\end{array}$ & $1.25^{\mathrm{a}} \pm 0.13$ & $\begin{array}{r}1.50^{b} \\
\pm 0.15\end{array}$ & $1.33^{c} \pm 0.14$ & $\begin{array}{l}1.80^{\mathrm{d}} \\
\pm 0.13\end{array}$ & $\begin{array}{c}2.00^{\mathrm{e}} \\
\pm 0.00\end{array}$ & \\
\hline \multicolumn{7}{|c|}{ Critical Difference (C.D.) for interval :0.08630 } \\
\hline \multicolumn{7}{|c|}{ Pooled Average Gr I to Gr IV on day 0:1.12 \pm 0.04} \\
\hline \multicolumn{7}{|c|}{ Critical Difference (C.D.) for Gr I to GR IV on day 0: 0.07013} \\
\hline
\end{tabular}

Table.5 Comparison of mean withdrawal reflex between conservative management groups (group I and group II), between surgical management groups (group III and group IV) and in different groups on Day 0

\begin{tabular}{|c|c|c|c|c|c|c|}
\hline \multirow{3}{*}{ Group } & \multicolumn{6}{|c|}{ Mean withdrawal reflex scores $( \pm \mathrm{SE})$} \\
\hline & \multicolumn{5}{|c|}{ Interval (Days) } & \multirow{2}{*}{$\begin{array}{l}\text { Pooled } \\
\text { average } \\
\text { (Groups) }\end{array}$} \\
\hline & Day 0 & Day 1 & Day 15 & Day 30 & Day 90 & \\
\hline Group - I & $1.68 \pm 0.17$ & $2.00 \pm 0.16$ & $2.55 \pm 0.16$ & $2.73 \pm 0.13$ & $2.86 \pm 0.08$ & $2.36 \pm 0.08$ \\
\hline Group - II & $1.28 \pm 0.11$ & $1.78 \pm 0.17$ & $2.56 \pm 0.15$ & $2.72 \pm 0.14$ & $2.72 \pm 0.14$ & $2.21 \pm 0.09$ \\
\hline $\begin{array}{c}\text { Pooled average } \\
\text { (Interval) }\end{array}$ & $1.50^{\mathrm{a}} \pm 0.11$ & $1.90^{b} \pm 0.12$ & $2.55^{c} \pm 0.11$ & $2.73^{d} \pm 0.09$ & $2.79^{\mathrm{e}} \pm 0.08$ & \\
\hline \multicolumn{7}{|c|}{ Critical Difference (C.D.) for interval: $\mathbf{0 . 0 3 9 8 3}$} \\
\hline Group - III & $1.00 \pm 0.00$ & $1.17 \pm 0.17$ & $2.67 \pm 0.21$ & $2.83 \pm 0.17$ & $3.00 \pm 0.00$ & $2.10 \pm 0.17$ \\
\hline Group - IV & $1.33 \pm 0.33$ & $2.00 \pm 0.37$ & $2.33 \pm 0.33$ & $3.00 \pm 0.00$ & $3.00 \pm 0.00$ & $2.23 \pm 0.18$ \\
\hline $\begin{array}{c}\text { Pooled average } \\
\text { (Interval) }\end{array}$ & $1.17^{\mathrm{a}} \pm 0.17$ & $1.58 \pm 0.23$ & $2.50^{c} \pm 0.19$ & $2.90^{\mathrm{df}^{\prime}} \pm 0.10$ & $3.00^{\mathrm{ef}} \pm 0.00$ & \\
\hline \multicolumn{7}{|c|}{ Critical Difference (C.D.) for interval :0.12513 } \\
\hline \multicolumn{7}{|c|}{ Pooled Average Gr I to Gr IV on day 0: $1.42 \pm 0.09$} \\
\hline
\end{tabular}


The mean withdrawal reflex score in group I on day 0 was $1.68 \pm 0.17$ which showed regular increasing trend, improved gradually and the score after 3 months was $2.86 \pm 0.08$ indicating near normal or strong reflex in this group. In group II as well, the improvement in score as regular and gradual and the score improved to $2.72 \pm 0.14$ at the end of observation period indicating similar improvement in both the groups within similar time frame. It was further observed that the differences between the group I and II were non-significant, however, there was significant differences between the scores at scheduled intervals indicating gradual and positive impact of the treatment. The mean withdrawal reflex score in group III on day 0 was $1.00 \pm 0.00$ which exhibited regular increasing trend up to 3 months and the score after 3 months was $3.00 \pm 0.00$ indicating that all the dogs showed normal strong withdrawal reflex. The group IV dogs showed irregular, undulating trend wherein the score improved from $1.33 \pm 0.33$ to $3.00 \pm 0.00$ on day 30 and it remained strong till the end of the observation period. Thus although both the groups indicated positive impact of surgeries, the animals of group IV showed better and early recovery on day 30 itself. It was also observed that the differences between the group III and IV were non-significant. However, the differences within the respective groups at different scheduled intervals were highly significant. Platt and Olby (2004) while observing the symptoms of T3-L3 spinal segment affections noted symptoms associated with UMN deficits of hindlimb charectorised by ataxia, proprioceptive deficit and paraplegia and increased muscle tone with normal to increased response of spinal reflexes.

Davis and Brown (2002) observed that the nociception reflex was an important prognostic factor and chances of recovery were much more in cases with positive nociception caudal to the lesion as also observed during the present investigation and the dogs that had voluntory motor reflexes in hindlimbs postoperatively had a significantly shorter time to ambulation as compared to dogs without motor reflexes. Similar observations have been noted by Levine et al., (2007) who opined that the nociception was a good indicator for positive outcome. During the present investigation, the loss of nociception was observed on the day of presentation or during the coure of treatment in 8 dogs suggering from IVDD and these cases did not show any improvement in their neurological deficits. Lahunta and Glass (2009) noted that loss of nociception occured as a step in neurological deterioration and indicated worst prognosis as these small nonmyelinated fibres lie in the propriospinal and spinoreticular tracts, located centrally in the white matter, close to gray matter. It was also noted during the present investigation that the dogs of surgical groups with intact nociception responded to the treatment and recovered early. Similar observations have been noted by Brisson et al., (2011) who noted that the prognosis after surgical intervention in dogs with intact nociception as considered by return to ambulation was fevourable in approximately $83-96 \%$ cases.

The present study of various spinal reflexes on the day of presentation and subsequently during the course of therapeutic management indicated that the spinal reflexes were very useful in diagnosing and localization of the lesions, the severity of lesions did not affect the outcome and and they were prognostic in the outcome of the cases. Macias et al., (2002) and Penning et al., (2006) also noted that the extent of spinal cord compression was not associated with the severity of the neurological dysfunction and the rate of onset and duration of clinical signs prior to presentation did not affect the prognosis, However, chronic cases were related to longer recovery period in spinal cord injuries. 


\section{References}

Brisson, B.A. 2010. Intervertebral disc disease in dogs. The Veterinary Clinics of North America. Small Animal practice 40: 829-858.

Bruce, C.W., B.A. Brosson, and Gyselinck, K. 2008. Spinal fracture and luxation in dogs and cats: a retrospective evaluation of 95 cases. Vet. Comp Orthop Traumatol, 21 (3): 280- 284.

De Lahunta, A. and Glass, E. 2009. Veterinary Neuroanatomy and Clinical Neurology. Third Edn., St. Louis, MO: Elsevier Saunders. pp 552.

Griffith, I. 1982. Spinal disease in the dog. In Pract., 4: 44-52.

Holmberg D. I., N. C.Palmer, D.Vanpelt, and Willan, A. R. 1990. A Comparison of Manual and Power-Assisted Thoracolumbar Disc Fenestration in Dogs. Veterinary Surgery. 19(5):323327.

McDonnell, J.J., S.R. Platt, andClayton, L.A.2001.Neurologic conditions causing lameness in companion animals. Veterinary Clinics of North America, Small Animal Practice 31(1):17-38.

McKee W.M. 2008. Thoracolumbar fractures and luxations 42 dogs. IVISwww.ivis.org

Reprinted in IVIS with the permission of the Congress Organizers 151. $14^{\text {th }}$ ESVOT Congress, Munich, 10th - 14th September. Referral Service, 78 Tanworth Lane, Solihull, West Midlands, B90 4DF, UK.

Muir, P. K.A. Johnson, P.A. Manley, and
Dueland, R.T. 1995. Comparison of hemilaminectomy and dorsal laminectomy for thoracolumbar intervertebral disc extrusion in dachshunds. J Small Anim. Pract. Aug; 36(8):360-7.

Nagaraja B. N.; M.S. Vasant, L. Ranganth, R.V. Prasad and Rao, S. 2014. Retrospective Studies on patterns of occurrence and treatment outcomes of traumatic posterior paralysis in dogs. Intas Polivet, 15 (1): 146-154.

Olby, N.J., T. Harris, K.R. Munana, T.M. Skeen, and Sharp, N.J.H. 2003. Longterm functional outcome of dogs with severe injuries of the thoraco- lumbar spinal cord: 87 cases (1996-2001). Journal of the American Veterinary Medical Association. 222(6):762-769.

Platt, S. and Olby, N.J. 2004. Paraperesis. In BSAVA Manual of Canine and Feline Neurology, $3^{\text {rd }}$ Edn., BSAVA: 237-264.

Shores, A and. Braund, K.G. 1993. Neurological examination and localization. In Text Book of Small Animal Surgery. Slatter D. (edtr), $\left(2^{\text {nd }}\right.$ Edn.), W.B. Sounders Company, Toronto. pp 2362.

Snedecor, G.W. and Cochran, W.G. 1994. Statistical methods, $6^{\text {th }}$ edition, Lowastate university press, Ames. pp 503.

Wilkens, B.E., R. Selcer, W.H. Adams, and Thomas, W.B. 1996. T9-T10 intervertebral discherniation in three dogs. Veterinary and Comparative Orthopaedics and Traumatology, 9(10): 177-178.

\section{How to cite this article:}

Khante, G.S., S.V. Upadhye, P.T. Jadhao, N.P. Dakshinkar, B.M. Gahlod, S.K. Sahatpure and Kurkure, N.V. 2019. Neurological Examination for Diagnosis and Prognosis of Spinal Disorders in Dogs. Int.J.Curr.Microbiol.App.Sci. 8(01): 485-493. doi: https://doi.org/10.20546/ijcmas.2019.801.052 